OPEN ACCESS

Edited by:

Chunbao Li,

Nanjing Agricultural University, China

Reviewed by:

Fusheng Chen,

Henan University of Technology, China

$\mathrm{NaNaWu}$

Academy of State Administration

of Grain, China

${ }^{*}$ Correspondence:

Weifen Qiu

weifenqiu711@163.com

Specialty section:

This article was submitted to

Food Microbiology,

a section of the journal

Frontiers in Microbiology

Received: 06 January 2018

Accepted: 06 June 2018

Published: 03 July 2018

Citation:

Ge Z, Du H, Gao Y and Qiu W (2018) Analysis on Metabolic Functions of Stored Rice Microbial Communities by BIOLOG ECO Microplates.

Front. Microbiol. 9:1375. doi: 10.3389/fmicb.2018.01375

\section{Analysis on Metabolic Functions of Stored Rice Microbial Communities by BIOLOG ECO Microplates}

\author{
Zhiwen Ge, Hengjun Du, Yulong Gao and Weifen Qiu* \\ Key Laboratory of Grains and Oils Quality Control and Processing, Collaborative Innovation Center for Modern Grain \\ Circulation and Safety, College of Food Science and Engineering, Nanjing University of Finance and Economics, Nanjing, \\ China
}

Microbial contamination has been a pervasive issue during the rice storage and triggers extensive researches. The metabolism of microorganisms was proved as an indicator to mirror the degree of microbial contamination. It is necessary to develop a scientific method to analyze the metabolism of rice microbial communities, thereby monitoring the microbial contamination. In this study, the metabolism of rice microbial communities in different storing-year were investigated by BIOLOG ECO microplates. The three rice samples were respectively stored for 1-3 years. The related indicators of BIOLOG ECO microplates were determined, including average well-color development (AWCD) of carbon sources and three metabolic functional diversity indices. The results showed that there were significant differences in the AWCD of all carbon sources among the three rice microbial communities $(p<0.05)$, and the functional diversity indices except Simpson index showed significant differences $(p<0.05)$. Additionally, the three rice microbial communities differed significantly in the metabolic utilization of carboxylic acids and miscellaneous $(p<0.05)$, and there were, however, no significant differences in the other four types of carbon sources. Furthermore, principal component analysis revealed that the microbial communities of stored rice had obviously different metabolic functions in different storage period. Therefore, the study indicated that the BIOLOG ECO microplate was applicable to evaluate the metabolic functions of rice microbial communities, and carboxylic acids and miscellaneous were two crucial parameters of carbon sources to identify the metabolic differences of microbial communities, a case in which it reflected the conditions of rice microbial contamination. Keywords: rice, microbial communities, metabolic functions, BIOLOG ECO microplates, AWCD, principal
component analysis

\section{INTRODUCTION}

Rice is one of the most important grain crops in the world, and China is the largest rice producer and consumer with yields of approximately $2.09 \times 10^{11} \mathrm{~kg}$, accounting for about $30 \%$ of the world's production in 2016. Rice is cultivated extensively in China, which is the staple food of Chinese. The storage period of rice is 3 years generally. During rice storage, however, microbial contamination is a common phenomenon, and it directly or indirectly affects the quality and safety of stored rice resulted from the production of mildew and rot as well as pigment secretion (FleuratLessard, 2017). The microbial species and quantities are closely related to the metabolic functions of microbial communities (Amador and Gorres, 2007). Therefore, in order to understand the role of 
microbial communities in rice storage, it is essential to analyze the metabolic functions of microbial communities (Preston-Mafham et al., 2002), which is meaningful for monitoring and controlling microbial contamination of rice as well.

The plate colony counting method, cell morphology, and RNA/DNA amplification technique were utilized traditionally to evaluate the quantities and structure of microorganisms in microbial communities. These methods, however, definitely had the disadvantages of complex operation protocols, timeconsuming assays, low accuracy, and poor repeatability (Jarvis, 2016; Kim et al., 2017). In this case, it is necessary to develop a new method to evaluate the status of microbial communities. The BIOLOG ECO microplate is a detector for the metabolic functions of microbial populations. It contains three sets of system, and each consists of a blank well and 31 different sole carbon source wells, which are closely relevant to the metabolic functions of microbial communities derived from environmental samples (Classen et al., 2003). The absorbance of each well is set as a variable of the sample (Ros et al., 2008; Zhang et al., 2014). The degree of substrate utilization in BIOLOG ECO microplates by microorganisms is measured based on absorbance detected by a redox indicator (Garland, 1996). Microorganisms produce free electrons during the process of using carbon sources, which makes a particular color reaction with the tetrazolium violet, and the depth of the chroma could reflect the carbon source utilization degree of the microorganisms (Agata et al., 2014). Different microorganisms are capable of using different carbon sources, namely the different metabolic functions, a case in which BIOLOG ECO microplate can be potentially applied in the analysis of microbial communities' status.

The BIOLOG ECO microplate is a relatively simple method, which is commonly applied to characterize the diversity of community-level physiological profiles (Rutgers et al., 2016; Feigl et al., 2017; Jiang et al., 2017). It is a novel method based on the biological and biochemical properties, thereby achieving quick characterization of the ecological status of environmental samples (Agata et al., 2014), such as sediments (Lopes et al., 2016), wastewater (Zhang et al., 2014), activated sludge (Paixão et al., 2007), and soils (Rutgers et al., 2016; Al-Dhabaan and Bakhali, 2017). However, there were little researches analyzing microbial functions of microbial communities by BIOLOG ECO microplates in the area of rice storage.

In this study, the BIOLOG ECO microplate was used to analyze the metabolic functions of rice microbial communities and explore the correlation between storage period and stored rice microbial communities, so as to provide a new method for the safe prevention and control of stored rice.

\section{MATERIALS AND METHODS}

\section{Collection of Rice Samples}

The rice samples were collected from grain depot of Hunan province, China. Rice was stored at $20 \pm 5^{\circ} \mathrm{C}$ and $\mathrm{RH} 50 \pm 5 \%$, which was a regular grain depot environment. The moisture content of rice was kept under 12\%. Each rice sample (150 g) was collected from the center and four corners of three layers of grain depot. Overall, three samples were analyzed. The three rice samples were respectively stored for 1-3 years and correspondingly marked as S1, S2, and S3. The rice was then stored in homogeneous bags at $4^{\circ} \mathrm{C}$ for the following experiment.

\section{Preparation of Sample Solution and Plate Cultivation}

The rice sample ( $25 \mathrm{~g}$ ) was added into $225 \mathrm{ml}$ of $0.85 \%$ strokephysiological saline solution. The mixture was oscillated and shaken for a hour at $4^{\circ} \mathrm{C}, 200 \mathrm{rpm}$ by Controlled Crystal Oscillator (RONGHUA, China), and then stewed for $3 \mathrm{~min}$. The three samples were separately diluted to a $10^{-3}$ gradient, and each sample was processed in triplicate. Each diluent $(150 \mu \mathrm{l})$ was added into wells of BIOLOG ECO microplates and the microplates were cultured at a constant temperature $\left(25^{\circ} \mathrm{C}\right)$ for 10 days. During cultivation, the ECO microplates were read absorbance values at $590 \mathrm{~nm}$ wavelength each $24 \mathrm{~h}$ using a Multifunctional Enzyme Label Tester (MOLECULAR DEVICES, United States).

\section{Determination of Average Well-Color Development Values}

Metabolism of the substrate in particular well-results in Formosan production, producing chroma change in the tetrazolium dye (Preston-Mafham et al., 2002). The capability of microorganisms to utilize different carbon sources in microbial communities was measured by average well-color development (AWCD) (Garland and Mills, 1991). Samples with larger variation were thought to have higher carbon source utilization capability and tend to have higher microbial abundance (Garland, 1997). The calculation formula for the AWCD is:

$$
\mathrm{AWCD}=\sum_{\mathrm{i}=1}^{\mathrm{n}}\left(\mathrm{C}_{\mathrm{i}}-\mathrm{R}\right) / \mathrm{n}
$$

In formula (1), $C_{i}$ is the absorbance value of each reaction well at $590 \mathrm{~nm}, \mathrm{R}$ is the absorbance value of the control well, and $\mathrm{n}$ is the number of wells. $\left(C_{i}-R\right)$ less than 0.06 of wells are calculated as zero (Classen et al., 2003).

\section{Calculation of Metabolic Functional Diversity Indices}

Zak et al. (1994) proposed that the calculation method based on functional diversity indices of BIOLOG ECO microplates could investigate the diversity of communities. Moreover, Keylock (2005) and Strong (2016) extended the concept of evenness to characterize the utilization levels and utilization patterns of microorganisms by carbon source.

(1) Shannon-Wiener diversity index $\left(\mathrm{H}^{\prime}\right)$ (Keylock, 2005; Spellerberg, 2008)

$$
\begin{gathered}
\mathrm{H}^{\prime}=-\sum \mathrm{P}_{\mathrm{i}} \ln \mathrm{P}_{\mathrm{i}} \\
\mathrm{P}_{\mathrm{i}}=\left(\mathrm{C}_{\mathrm{i}}-\mathrm{R}\right) / \sum\left(\mathrm{C}_{\mathrm{i}}-\mathrm{R}\right)
\end{gathered}
$$

The $P_{i}$ represents the ratio of the absorbance value in the $i^{\text {th }}$ ( 1 to 31 ) well to the total absorbance values of all wells. 
(2) Shannon evenness index (E) (Keylock, 2005)

$$
\mathrm{E}=\mathrm{H}^{\prime} / \ln \mathrm{S}
$$

$S$ represents the total number of utilized carbon sources (31 carbon sources), the number of wells that vary in color.

(3) Simpson diversity index (D)

$$
\mathrm{D}=1-\sum \mathrm{P}_{\mathrm{i}}^{2}
$$

The above indices reflected the metabolic functional diversity of microbial communities, which was similar to the measurements of diversity indices in general ecology.

\section{Principal Component Analysis}

A BIOLOG ECO microplate contains 31 carbon sources, which are made up with six kinds of carbon sources, including carboxylic acids, carbohydrates, amino acids, polymers, miscellaneous, and amines/amides. In order to avoid the influence on statistical analysis results, we need to convert the absorbance data into $\mathrm{R}_{\mathrm{si}}$ value to perform principal component analysis (PCA). The calculation formula for the $\mathrm{R}_{\mathrm{si}}$ is:

$$
\mathrm{R}_{\mathrm{si}}=\left(\mathrm{C}_{\mathrm{i}}-\mathrm{R}\right) / \mathrm{AWCD}
$$

In formula (6), $C_{i}$ is the absorbance value of each reaction well at different incubation time at $590 \mathrm{~nm}$ excluding the control well, and $\mathrm{R}$ is the absorbance value of the control well.

In this experiment, measuring the absorbance values of BIOLOG ECO microplates on day 8 were used for the PCA of microbial communities' metabolic functional diversity.

\section{Statistical Analysis}

All experiments were performed in triplicate, and the results were expressed as means \pm standard deviations. Origin 8.5.1 was used to create pictures, and SIMCA 14.1 was used to conduct PCA. Results from one-way analysis of variance (ANOVA) were considered significant when the $p$-value was less than 0.05 .

\section{RESULTS AND DISCUSSION}

\section{The AWCD of All Carbon Sources in Rice Microbial Communities Within Incubation Time}

Generally, the degree of carbon source oxidation was proportional to the metabolic capability of corresponding microbes, which could be characterized by AWCD (Garland and Mills, 1991). The AWCD (AWCD of all carbon sources) of the three rice microbial communities are shown in Figure 1. The results showed that the $\mathrm{AWCD}_{\mathrm{a}}$ of all stored rice samples exhibited an apparent lag phase in the first day. Then the average absorbance of all three samples in microplates increased significantly, demonstrating that the three microbial communities were capable of metabolizing organic substrates in BIOLOG ECO microplates. The period selected for metabolic activity analysis was from day 1 to day 8 , and the slopes of

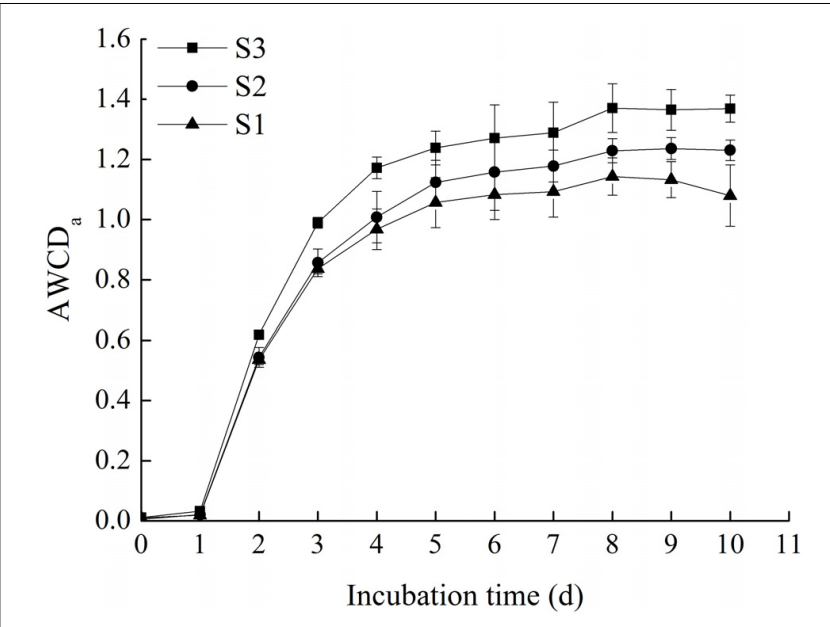

FIGURE 1 | The AWCD of all carbon sources in stored rice microbial communities within incubation time (the original data available in Supplementary Table 1).

$\mathrm{AWCD}_{\mathrm{a}}$ curves within this period represented average metabolic rates of the microbial communities (Kong et al., 2013). During the cultivating period, the increase rate of $\mathrm{AWCD}_{\mathrm{a}}$ was slower after 5 days. Meanwhile, the $\mathrm{AWCD}_{\mathrm{a}}$ reached to the peaks on day 8 and the metabolic utilization capability of microbial communities tended to be stable (Zhang et al., 2014), stating that all cultivable microorganisms enable to steadily use carbon sources during the stable period (Miyake et al., 2016). The changes regulation of $\mathrm{AWCD}_{\mathrm{a}}$ within incubation time was comparable with the studies of Zhang et al. (2014).

Among the three samples, the metabolic rate of S3 was faster than S1 and S2. The AWCD $\mathrm{A}_{\mathrm{a}}$ of S3 increased from 0 to around 1.37 after 8 days. S1 showed the lowest metabolic rate of the substrates in the BIOLOG ECO microplate, and the $\mathrm{AWCD}_{\mathrm{a}}$ increased to around 1.13 when it got to the stable, which indicated that the utilization of substrates by $\mathrm{S} 1$ was less efficient than the others. This illuminated that the storage length of time had an obvious effect on promoting metabolic activity of microorganisms in stored rice. Besides, in the stable period, there were significant differences in the $\mathrm{AWCD}_{\mathrm{a}}$ among three rice microbial communities $(p<0.05)$, and the order was S3 $>$ S2 $>$ S1, which suggested that the longer storage length of time was, the higher metabolic capability of rice microbial community was. The similar research and method was reported by Sun et al. (2012).

\section{Metabolism of Different Biochemical Categories of Substrates}

According to the biochemical properties of carbon sources, the 31 substrates in the BIOLOG ECO microplates were assigned into six categories, including carboxylic acids, carbohydrates, amino acids, polymers, miscellaneous, and amines/amides (Zhang et al., 2014), the details were described in Table 2. The AWCD of different types of carbon sources were classified and analyzed in the experiment. 
The Figure 2 showed the AWCD of carboxylic acids, carbohydrates, amino acids, polymers, miscellaneous, and amines/amides. The results indicated that the utilization of six types of carbon sources by microbes presented an increasing trend with the prolongation of incubation time. For carbohydrates, amino acids, polymers and amines/amides, there were no significant difference in the utilization among the three microbial communities. The utilization of carboxylic acids and

TABLE 1 | Comparison of metabolic functional diversity indices of the rice microbial communities.

\begin{tabular}{lccc}
\hline Sample & $\begin{array}{c}\text { Shannon } \\
\text { diversity (H') }\end{array}$ & $\begin{array}{c}\text { Shannon } \\
\text { evenness (E) }\end{array}$ & $\begin{array}{c}\text { Simpson } \\
\text { diversity (D) }\end{array}$ \\
\hline S1 & $3.378 \pm 0.005 \mathrm{a}$ & $0.984 \pm 0.002 \mathrm{a}$ & $0.962 \pm 0.001 \mathrm{a}$ \\
S2 & $3.313 \pm 0.017 \mathrm{c}$ & $0.965 \pm 0.005 \mathrm{c}$ & $0.964 \pm 0.002 \mathrm{a}$ \\
S3 & $3.340 \pm 0.004 \mathrm{~b}$ & $0.973 \pm 0.001 \mathrm{~b}$ & $0.963 \pm 0.001 \mathrm{a}$
\end{tabular}

Data in the table are mean $\pm S E, n=3$. Using Duncan's multiple range test of diversity indices separately, different letters of each column represent the significant difference at $p<0.05$. miscellaneous by the three rice microbial communities, however, differed significantly $(p<0.05)$, and the utilization capability order was S3 $>$ S2 $>$ S1, thereby clarifying that the microbial community of rice increased the utilization of carboxylic acids and miscellaneous with the extendence of storage period.

For different microbial communities, the capability utilizations of six-type carbon sources were different. The AWCD of carbohydrates was the highest, and the lowest was amines/amides, thereby illustrating that carbohydrates were the carbon sources with the highest degree of metabolic utilization, and the lowest degree of metabolic utilization was amines/amides. The results were similar to the findings reported by previous researches, the utilization of carbohydrates was relatively higher than other substrates among the six types of carbon sources, whereas the lowest utilization substrates differed from microbial communities (Kong et al., 2013; Zhang et al., 2014).

In general, through BIOLOG ECO microplates, the metabolic rates of carbon sources were determined by calculating a single value (AWCD) at a single time point, which demonstrated and made a clear comparison of stored rice microbial communities.

TABLE 2 | The 31 kinds of carbon substrates loaded on the first and second principal component in analysis of BIOLOG ECO microplates data.

\begin{tabular}{|c|c|c|c|c|c|}
\hline Chemical guild & Plate number & Substrates & Chemical formula & PC1 & PC2 \\
\hline & G2 & Glucose-1-phosphate & $\mathrm{C}_{6} \mathrm{H}_{13} \mathrm{O}_{9} \mathrm{P}$ & 0.0033 & 0.3322 \\
\hline \multirow[t]{3}{*}{ Polymers } & $\mathrm{C} 1$ & Tween 40 & - & 0.2398 & -0.0996 \\
\hline & D1 & Tween 80 & - & 0.0500 & -0.1901 \\
\hline & E1 & $\alpha$-Cyclodextrin & $\mathrm{C}_{36} \mathrm{H}_{60} \mathrm{O}_{30}$ & 0.1103 & -0.1781 \\
\hline \multirow[t]{6}{*}{ Carbohydrates } & G1 & D-Cellobiose & $\mathrm{C}_{12} \mathrm{H}_{12} \mathrm{O}_{11}$ & 0.2292 & 0.0885 \\
\hline & $\mathrm{H} 1$ & $\alpha$-D-Lactose & $\mathrm{C}_{12} \mathrm{H}_{12} \mathrm{O}_{11}$ & 0.2426 & 0.1402 \\
\hline & $\mathrm{A} 2$ & Methyl-D-glucoside & $\mathrm{C}_{7} \mathrm{H}_{14} \mathrm{O}_{6}$ & 0.2489 & 0.0717 \\
\hline & B2 & D-Xylose & $\mathrm{C}_{5} \mathrm{H}_{10} \mathrm{O}_{5}$ & 0.1942 & -0.1073 \\
\hline & $\mathrm{C} 2$ & i-Erythritol & $\mathrm{C}_{4} \mathrm{H}_{10} \mathrm{O}_{4}$ & 0.2296 & -0.0517 \\
\hline & D2 & D-Mannitol & $\mathrm{C}_{6} \mathrm{H}_{14} \mathrm{O}_{6}$ & 0.1226 & -0.1551 \\
\hline & B3 & D-Galacturonic acid & $\mathrm{C}_{6} \mathrm{H}_{10} \mathrm{O}_{7}$ & 0.1217 & 0.1913 \\
\hline & $\mathrm{C} 3$ & 2-Hydroxy benzoic acid & $\mathrm{C}_{7} \mathrm{H}_{6} \mathrm{O}_{3}$ & -0.1194 & -0.2752 \\
\hline & D3 & 4-Hydroxy benzoic acid & $\mathrm{C}_{7} \mathrm{H}_{6} \mathrm{O}_{3}$ & 0.0291 & 0.3345 \\
\hline & E3 & $\gamma$-Hydroxy butyric acid & $\mathrm{C}_{4} \mathrm{H}_{8} \mathrm{O}_{3}$ & -0.1384 & 0.2710 \\
\hline & F3 & Itaconic acid & $\mathrm{C}_{5} \mathrm{H}_{6} \mathrm{O}_{4}$ & 0.1027 & -0.1428 \\
\hline & G3 & $\alpha$-Keto butyric acid & $\mathrm{C}_{4} \mathrm{H}_{6} \mathrm{O}_{3}$ & 0.0846 & 0.2812 \\
\hline & $\mathrm{H} 3$ & D-Malic acid & $\mathrm{C}_{4} \mathrm{H}_{6} \mathrm{O}_{5}$ & 0.1845 & 0.1137 \\
\hline \multirow[t]{4}{*}{ Amino acids } & A4 & L-Arginine & $\mathrm{C}_{4} \mathrm{H}_{14} \mathrm{~N}_{4} \mathrm{O}_{2}$ & -0.2298 & 0.1084 \\
\hline & B4 & L-Asparagine & $\mathrm{C}_{4} \mathrm{H}_{8} \mathrm{~N}_{2} \mathrm{O}_{3}$ & 0.1433 & -0.0043 \\
\hline & $\mathrm{C} 4$ & L-Phenylalanine & $\mathrm{C}_{9} \mathrm{H}_{11} \mathrm{NO}_{2}$ & -0.0231 & -0.2425 \\
\hline & D4 & L-Serine & $\mathrm{C}_{3} \mathrm{H}_{7} \mathrm{NO}_{3}$ & 0.2494 & 0.0564 \\
\hline
\end{tabular}



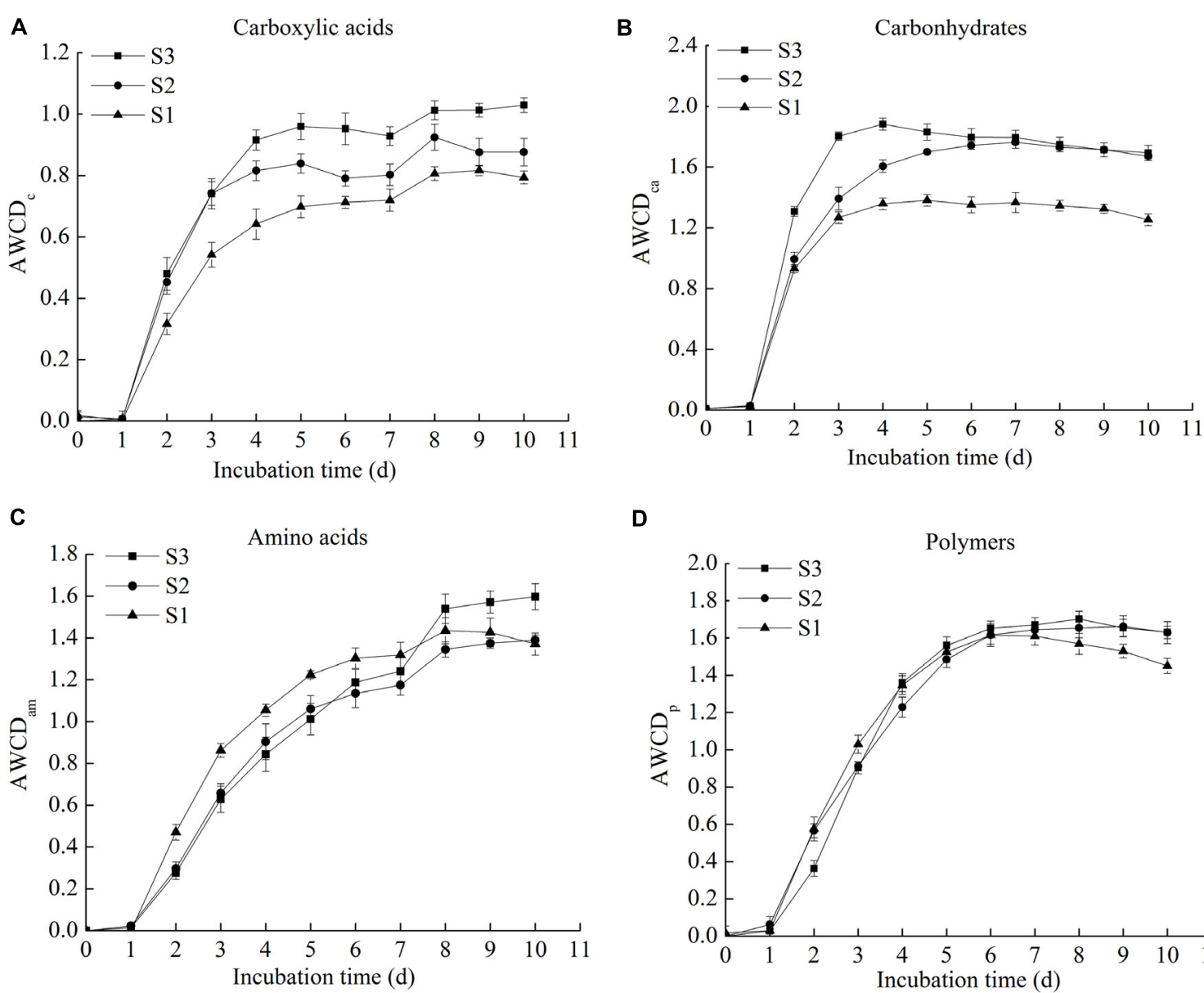

D

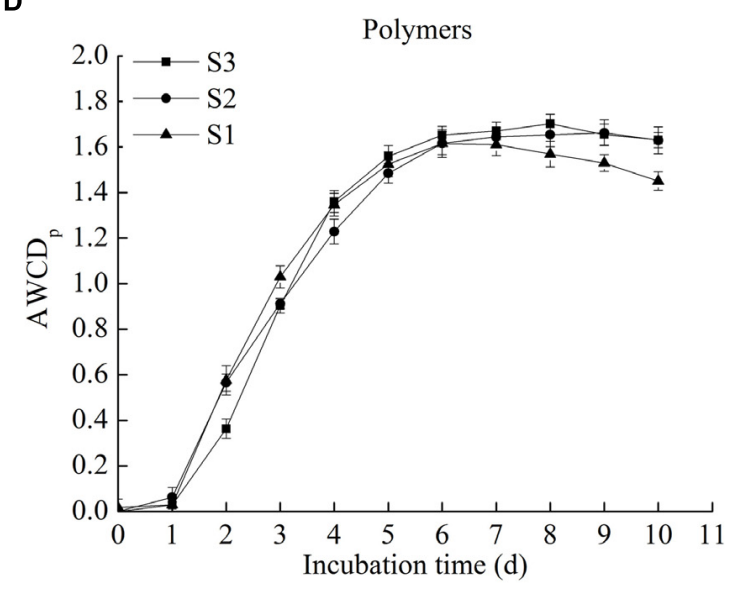

E

$\mathbf{F}$
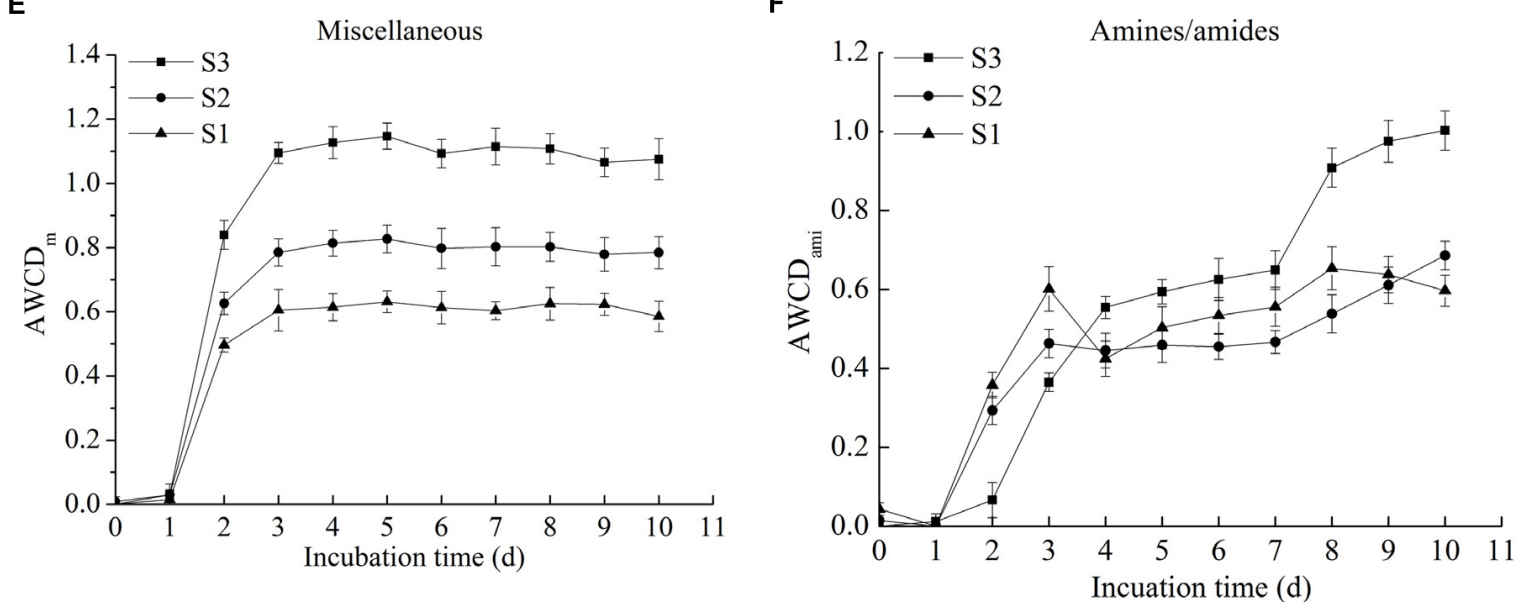

FIGURE 2 | The AWCD of six types of carbon sources in three stored rice microbial communities, including carboxylic acids (A), carbohydrates (B), amino acids (C), polymers (D), miscellaneous (E), and amines/amides (F) (the original data available in Supplementary Table 2).

\section{Comparison of Metabolic Functional Diversity Indices}

The metabolic functional diversity of microbial communities were actually reflected by functional diversity indices (Zhanga et al., 2013). The Shannon diversity index $\left(\mathrm{H}^{\prime}\right)$, Shannon evenness index (E), and Simpson index (D) of rice microbial communities were showed in Table 1. Shannon diversity index $\left(\mathrm{H}^{\prime}\right)$ is greatly influenced by species richness of communities (Sun et al., 2012). A higher diversity index indicated that the stored rice microbial community metabolic functional diversity was larger 
(Strong, 2016). The higher the Shannon evenness index (E) was, the more evenly the individuals distributed (Zhanga et al., 2013). Simpson index (D) proposed by Simpson (1949) is greatly reflected by the most common species.

Duncan's multiple range test was separately used in these indices. Table 1 clearly indicated that two indices except Simpson index (D) of the rice microbial communities had significant difference $(p<0.05)$. The Shannon diversity and evenness index of S1 was highest, followed by sample S3 and S2, indicating that the species richness and evenness of microorganisms in stored rice were relatively high in the early stage of storage. It tended to decrease first and then increased during the storage. Laca et al. (2006) also reported the similar results in their research. They explained that rice carried many field microbes at the beginning of storage, and then field microbes decreased with the extension of storage period, and, meanwhile, the storage microbes increased. However, as shown in Table 1, there was no significant difference in Simpson index (D), which manifested that the most common species of the three rice microbial communities were similar, such as fungus of Aspergillums, Penicillium and Mucor, as observed in previous research (Magan, 2006). Furthermore, the storage length of time has no impact on the common species.

\section{PCA of Carbon Source Metabolization}

Principal component analysis was used to evaluate the carbon source metabolization of microbial communities in a certain environment (Graham and Haynes, 2005; Kong et al., 2013). Some researchers had reported that PCA was applied in the multivariate analysis and enabled to clearly differentiate samples
(Felipe-Sotelo et al., 2008; Illian et al., 2009). After dimension reduction, the difference of metabolic characteristics in rice microbial communities were directly reflected by the position of the points in the principal vector space (Graham and Haynes, 2005; Kim et al., 2017).

As shown in Figure 3, the multivariate vectors were transformed into two uncorrelated principal component vectors. PC1 presented $43.1 \%$ of total variability, and PC2 described $20.42 \%$. For the rice microbial communities, the point position of S1, S2, and S3 were certainly different. As Reddy et al. (2009) stated, the growth and changes of microbial species always occurred during the rice storage period, which led to the difference of capability utilization of microbial communities.

Table 2 showed the loading scores of 31 carbon sources in the first two principal components. The higher loading scores were, the larger effects of carbon source on the principal components were. The sample distribution in the PC axis was relevant to carbon source substrates capability utilization of stored rice microbes (Zhanga et al., 2013). From the PCA results in Table 2, it could be seen that there were 17 kinds of carbon sources had mainly impacts on the PC1. The 17 kinds of carbon sources included five kinds of carbohydrates, four kinds of amino acid, three kinds of carboxylic acid, two kinds of miscellaneous, polymers and amines/amides. These results indicated that the carbon sources with impacts on the PC1 were mainly carbohydrates, amino acid, and miscellaneous. Furthermore, there were mainly 14 types of carbon sources with effects on the PC2, including six kinds of carboxylic acids, three kinds of carbohydrates, two kinds of amino acids and polymers, a kind of miscellaneous. Thereby, the carboxylic acids made the major effects on the PC2.

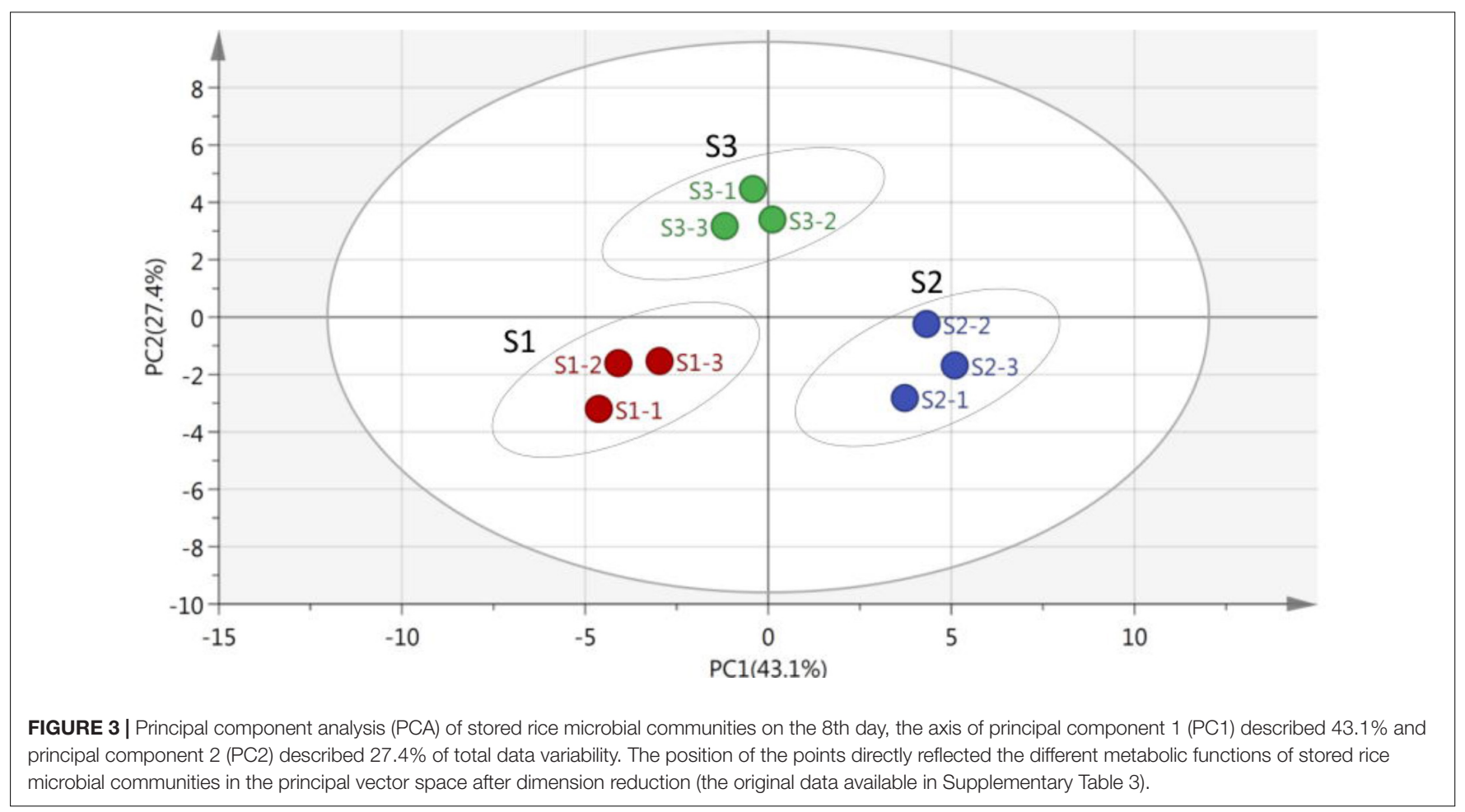


From the results of carbon sources analysis above, it was obvious that the carbon sources utilized by rice microbes were carbohydrates, amino acid, miscellaneous, and carboxylic acids. The similar analysis method was reported by Zhanga et al. (2013).

\section{CONCLUSION}

In present study, the metabolic functions of microbial communities of rice with different storage years were investigated and analyzed by BIOLOG ECO microplates. With the extension of storage period, the utilization of rice microbial communities for carboxylic acids and miscellaneous increased. Among the six types of carbon sources, the utilization of carbohydrates was relatively higher than other substrates. The metabolic functional diversity indices showed that there were differences among the three rice microbial communities, whereas the most common species of them were similar. Furthermore, carbon sources utilization of the three microbial communities were certainly different, and the carbon sources mainly utilized by stored rice microbes were carbohydrates, amino acid, miscellaneous, and carboxylic acids.

Therefore, to draw a conclusion, this study illustrated that BIOLOG ECO microplates were capable of preceding a quick and accurate determination of metabolic functions of rice microbial communities, which provided a novel method for safe prevention and control of stored rice. However, BIOLOG ECO microplates are unable to evaluate the microbial communities' structure of stored rice. The evaluation of dominant species as well as

\section{REFERENCES}

Agata, G., Magdalena, F., and Karolina, O. (2014). The application of the biolog ecoplate approach in ecotoxicological evaluation of dairy sewage sludge. Appl. Biochem. Biotechnol. 174, 1434-1443. doi: 10.1007/s12010-014-1131-8

Amador, J. A., and Gorres, J. H. (2007). Microbiological characterization of the structures built by earthworms and ants in an agricultural field. Soil Biol. Biochem. 39, 2070-2077. doi: 10.1016/j.soilbio.2007.03.010

Al-Dhabaan, F. A. M., and Bakhali, A. H. (2017). Analysis of the bacterial strains using biolog plates in the contaminated soil from Riyadh community. Saudi J. Biol. Sci. 24, 901-906. doi: 10.1016/j.sjbs.2016.01.043

Classen, A. T., Boyle, S. I., Haskins, K. E., Overby, S. T., and Hart, S. C. (2003). Community-level physiological profiles of bacteria and fungi: plate type and incubation temperature influences on contrasting soils. FEMS Microbiol. Ecol. 44, 319-328. doi: 10.1016/S0168-6496(03)00068-0

Feigl, V., Ujaczki, É., Vaszita, E., and Molnár, M. (2017). Influence of red mud on soil microbial communities: application and comprehensive evaluation of the biolog ecoplate approach as a tool in soil microbiological studies. Sci. Total Environ. 595, 903-911. doi: 10.1016/j.scitotenv.2017.03.266

Felipe-Sotelo, M., Tauler, R., Vives, I., and Grimalt, J. O. (2008). Assessment of the environmental and physiological processes determining the accumulation of organochlorine compounds in European mountain lake fish through multivariate analysis (PCA and PLS). Sci. Total Environ. 404, 148-161. doi: 10.1016/j.scitotenv.2008.06.020

Fleurat-Lessard, F. (2017). Integrated management of the risks of stored grain spoilage by seedborne fungi and contamination by storage mould mycotoxins An update. J. Stored Prod. Res. 71, 22-40. doi: 10.1016/j.jspr.2016.10.002

Garland, J. L. (1996). Analytical approaches to the characterization of samples of microbial communities using patterns of potential C source utilization. Soil Biol. Biochem. 28, 213-221. doi: 10.1016/0038-0717(95)00112-3 species distribution and difference of three stored rice microbial communities need to be studied in the next work.

\section{AUTHOR CONTRIBUTIONS}

ZG: conceived and designed the experiments, performed the experiments, data analyses and wrote the manuscript, and contributed the experimental materials. ZG, HD, and YG: revised the manuscript, played an important role in interpreting the results, and helped perform the analysis with constructive discussions. WQ: approved the final version.

\section{FUNDING}

This work was financially supported by the National Key Research and Development Program of China (Grant No. 2016YFD0401003), the Postgraduate Research \& Practice Innovation Program of Jiangsu Province (Grant No. KYCX17_1217), and the Priority Academic Program Development of Jiangsu Higher Education Institutions (Grant No. PAPD).

\section{SUPPLEMENTARY MATERIAL}

The Supplementary Material for this article can be found online at: https://www.frontiersin.org/articles/10.3389/fmicb. 2018.01375/full\#supplementary-material

Garland, J. L. (1997). Analysis and interpretation of community-level physiological profiles in microbial ecology. FEMS Microbiol. Ecol. 24, 289-300. doi: 10.1111/ j.1574-6941.1997.tb00446.x

Garland, J. L., and Mills, A. L. (1991). Classification and characterization of heterotrophic microbial communities on the basis of patterns of communitylevel sole-carbon-source utilization. Appl. Environ. Microbiol. 57, 2351-2359.

Graham, M. H., and Haynes, R. J. (2005). Catabolic diversity of soil microbial communities under sugarcane and other land uses estimated by Biolog and substrate-induced respiration methods. Appl. Soil Ecol. 29, 155-164. doi: 10.1016/j.apsoil.2004.11.002

Illian, J. B., Prosser, J. I., Baker, K. L., and Rangel-Castro, J. I. (2009). Functional principal component data analysis: a new method for analysing microbial community fingerprints. J. Microbiol. Methods 79, 89-95. doi: 10.1016/j.mimet. 2009.08.010

Jarvis, B. (ed.). (2016). "Errors associated with colony count procedures," in Statistical Aspects of the Microbiological Examination of Foods, (Cambridge, MA: Academic Press), 119-140. doi: 10.1016/B978-0-12-803973-1.00007-3

Jiang, L. L., Han, G. M., Lan, Y., Liu, S. N., Gao, J. P., Yang, X., et al. (2017). Corn cob biochar increases soil culturable bacterial abundance without enhancing their capacities in utilizing carbon sources in Biolog eco-plates. J. Integr. Agric. 16, 713-724. doi: 10.1016/S2095-3119(16)61338-2

Keylock, C. J. (2005). Simpson diversity and the shannon-wiener index as special cases of a generalized entropy. Oikos 109, 203-207. doi: 10.1111/j.0030-1299. 2005.13735.x

Kim, J. W., Rehmann, L., and Ray, M. B. (2017). Development of microalgal bioassay based on the community level physiological profiling (CLPP). Algal Res. 25, 47-53. doi: 10.1016/j.algal.2017.04.037

Kong, X., Wang, C., and Ji, M. (2013). Analysis of microbial metabolic characteristics in mesophilic and thermophilic biofilters using Biolog plate technique. Chem. Eng. J. 230, 415-421. doi: 10.1016/j.cej.2013.06.073 
Laca, A., Mousia, Z., Diaz, M., Webb, C., and Pandiella, S. S. (2006). Distribution of microbial contamination within cereal grains. J. Food Eng. 72, 332-338. doi: 10.1016/j.jfoodeng.2004.12.012

Lopes, J., Peixoto, V., Coutinho, A., Mota, C., and Fernandes, S. (2016). "Determination of the community-level physiological profiles (CLPP) using BiologTM ECO-plates in the river Lima estuary sediments (Northern Portugal)," in Proceedings of the International Meeting on Marine Research, Peniche.

Magan, N. (2006). Mycotoxin contamination of food in Europe: early detection and prevention strategies. Mycopathologia 162, 245-253. doi: 10.1007/s11046-0060057-2

Miyake, H., Maeda, Y., Ishikawa, T., and Tanaka, A. (2016). Calorimetric studies of the growth of anaerobic microbes. J. Biosci. Bioeng. 122, 364-369. doi: 10.1016/ j.jbiosc.2016.02.006

Paixão, S. M., Sàágua, M. C., Tenreiro, R., and Anselmo, A. M. (2007). Assessing microbial communities for a metabolic profile similar to activated sludge. Water Environ. Res. 79, 536-546. doi: 10.2175/106143006X123148

Preston-Mafham, J., Boddy, L., and Randerson, P. F. (2002). Analysis of microbial community functional diversity using sole-carbon-source utilisation profiles a critique. FEMS Microbiol. Ecol. 42, 1-14.

Reddy, K. R. N., Reddy, C. S., and Muralidharan, K. (2009). Potential of botanicals and biocontrol agents on growth and aflatoxin production by Aspergillus flavus infecting rice grains. Food Control 20, 173-178. doi: 10.1016/j.foodcont.2008. 03.009

Ros, M., Goberna, M., Pascual, J. A., Klammer, S., and Insam, H. (2008). 16S rDNA analysis reveals low microbial diversity in community level physiological profile assays. J. Microbiol. Methods 72, 221-226. doi: 10.1016/j.mimet.2008. 01.003

Rutgers, M., Wouterse, M., Drost, S. M., Breure, A. M., Mulder, C., Stone, D., et al. (2016). Monitoring soil bacteria with community-level physiological profiles using Biolog ECO-plates in the Netherlands and Europe. Appl. Soil Ecol. 97, 23-35. doi: 10.1016/j.apsoil.2015.06.007
Simpson, E. H. (1949). Measurement of Diversity. Nature 163:688. doi: 10.1038/ $163688 \mathrm{a} 0$

Spellerberg, I. F. (2008). Shannon-Wiener index. Encycl. Ecol. 3249-3252. doi: 10.1016/B978-008045405-4.00132-4

Strong, W. L. (2016). Biased richness and evenness relationships within ShannonWiener index values. Ecol. Indic. 67, 703-713. doi: 10.1016/j.ecolind.2016. 03.043

Sun, Y. H., Yang, Z. H., Zhao, J. J., and Li, Q. (2012). Functional diversity of microbial communities in sludge-amended soils. Phys. Procedia 33, 726-731. doi: 10.1016/j.phpro.2012.05.127

Zak, J. C., Willig, M. R., Moorhead, D. L., and Wildman, H. G. (1994). Functional diversity of microbial communities: a quantitative approach. Soil Biol. Biochem. 26, 1101-1108. doi: 10.1016/0038-0717(94)90131-7

Zhang, T. Y., Wu, Y. H., Zhuang, L. L., Wang, X. X., and Hu, H. Y. (2014). Screening heterotrophic microalgal strains by using the Biolog method for biofuel production from organic wastewater. Algal Res. 6, 175-179. doi: 10.1016/j.algal.2014.10.003

Zhanga, H., Song, X., Yang, D., Qiao, J., Zhang, J., and Zhao, S. (2013). Changes in soil microbial functional diversity under different vegetation restoration patterns for Hulunbeier Sandy Land. Acta Ecol. Sin. 33, 38-44. doi: 10.1016/ j.chnaes.2012.12.006

Conflict of Interest Statement: The authors declare that the research was conducted in the absence of any commercial or financial relationships that could be construed as a potential conflict of interest.

Copyright (C) $2018 \mathrm{Ge}, \mathrm{Du}$, Gao and Qiu. This is an open-access article distributed under the terms of the Creative Commons Attribution License (CC BY). The use, distribution or reproduction in other forums is permitted, provided the original author(s) and the copyright owner(s) are credited and that the original publication in this journal is cited, in accordance with accepted academic practice. No use, distribution or reproduction is permitted which does not comply with these terms. 